\title{
A simple worst case analysis for estimation of correct scanning rate in a micrometeorological experiment
}

\author{
C. J. Stigter ${ }^{1}$, J. G. Lengkeek and J. Kooijman ${ }^{2}$ \\ Department of Physics and Meteorology, Agricultural University, Wageningen, the \\ Netherlands
}

Accepted for publication: 18 September 1975

Index words: micrometeorology, sample frequency, scanning rate

\section{Summary}

After review of confusing literature debates, a simple way is demonstrated to estimate influence of sample frequency on means of scanned meteorological variables. For a high time-eonstant thermometer the influence of high scanning rates is demonstrated to be low in relation to chosen approximations of the true mean by a lower scanning rate. For a very low time-constant thermocouple psychrometer and a low timeconstant air movement meter the influence of several lower scanning rates is demonstrated to be low in comparison with a chosen approximation of the true mean by a relatively high scanning rate. As no Fourier analysis is applied in this simple method, definite assessment of aliasing errors is in theory only approximated although other results point into the direction that such an analysis would not change much the error examples given.

\section{Introduction}

In recent years our capability to deal in research experimentally with the climate outdoors has grown. In relation to the (micro)-climate of crops this may be seen from, among other things, a growing literature on experiments and resulting theories regarding crop microclimate and plant response to climatic factors in the field (e.g. San Pietro et al., 1967; Eckardt, 1968; Anon., 1968; Eastin et al., 1969; Sétlik, 1970; Wareing and Cooper, 1971; Lemon et al., 1971; Sesták et al., 1971; Paltridge et al., 1972; Stigter, 1972; Slatyer, 1973; Monteith, 1973; Kreeb, 1974; Rosenberg, 1974; Smith, 1975a, 1975b; de Vries \& Afgan, 1975).

Because of variability in space and time and interrelationship of the (micro)meteorological parameters, special requirements have to be met regarding the num-

1 Present address: Department of Physics, University of Dar es Salaam, P.o. Box 35063, Dar es Salaam, Tanzania.

2 Now with FAO (Rome). 
ber of almost simultaneous measurements to be made in a crop climate experiment (e.g. Bradley \& Denmead, 1967; Paltridge et al., 1972). For this reason electronic scanning equipment, measuring consecutively a great number of sensors in a relatively short period of time, has become more or less standard in such experiments.

Although extremely high-speed scanning is possible and necessary for the exploration of atmospheric fine structure (e.g. Luxton et al., 1967), demands for scanning speed in determination of means of meteorological parameters inside and above crop canopies are less rigorous (Tanner, 1963). In a lot of situations ten minutes to hourly means of the parameters are wanted. We want to deal here with a simple example of estimating in practice a correct scanning rate in these latter cases.

\section{Information wanted}

The problem of data logging and scanning rate in micrometeorological experiments was preliminary put forward by Suomi (1957) and Tanner (1963) and dealt with in more details by Byrne (1970). On the basis of these publications the problem was discussed by Fuchs (1972) and Byrne (1972).

Sampling is a particular form of modulation and can be safely applied to bandlimited signals provided Shannon's sample theorem is valid (Karbowiak, 1967). This theorem states that distortion-free recovery of the original signal is possible if a signal of band width $\pm f_{b} H z$ is sampled with a frequency $f_{s}>2 f_{b}$. Tanner (1963) brought this sample frequency in relation with the time constant $\tau$ of a simple exponential response sensor. But neither he nor Suomi (1957) did take into account the possible aliasing errors resulting from higher frequency components still present in the output from the sensor (Karbowiak, 1967; Byrne, 1970,1972). When originally existing in the unmodified parameter signal to be measured, these frequencies may poison the output of a sensor or other filter.

Fuchs (1972) made the point that, in the case of these high-frequency components being present, the introduction of amplitude attenuation factors for these frequencies in the filter output would give the possibility for estimating the remaining signal errors. Byrne (1972) rightly replied that this would be impossible without knowing exactly the frequencies making up the signal concerned. However after having made this statement the author gives an example of a cut-off frequency which stems from a filter output not specifically being analysed for remnants of high-frequency components.

Moreover Byrne as well as Fuchs apply this attenuation concept to an example from Suomi (1957), also quoted by Tanner (1963). As in this example only hourly means are discussed, this seems somewhat confusing. Neither does the example apply to recovering of the complete signal sampled, as filtered out by the highconstant temperature sensor (as was already stated by Tanner), nor do we know the highest Fourier frequency components of the unmodified temperature signal. (The small difference between the values of the attenuation factors calculated by Fuchs $(0.44)$ and by Byrne $(0.52)$ for this same case stems from a difference in the applied effective cut-off frequency.) 
To solve the problem of determining a correct scanning rate in micrometeorological practice, we believe that it is necessary to separate two details:

1. The determination of influence of sampling frequency on estimation of true means over a certain specified period, taking an estimated rule-of-thumb frequency for a good approximation of that true mean. One may take, for example, approximately the Shannon frequency for a simple exponential sensor without higher components present, although the latter assumptions are known to be illegal in principle;

2. The estimation of influence of higher-frequency components on the signal sampled with a rate determined with the Shannon-like rule-of-thumb used in 1 . This can only be done by Fourier analysis of the continuous signal or a sampled signal (with a rate equal to or higher than the rule-of-thumb value). In the latter case sample frequency is limiting the band width which can be observed.

For our experiments under concern, the outcome of point 2 is only of importance if the approximations of the true mean of a signal, obtained by sampling with different frequencies, are influenced by the presence of high Fourier components. If so, we are interested how they are influenced in dependence of the sample frequency. A definite answer to this question can only be given after detailed examination of point 2 and will be dealt with elsewhere. In this paper we restrict ourselves to showing a simple way of estimating influence of sample frequency on approximated true means of signals of high time-constant temperature sensors and low time-constant humidity and air movement sensors.

\section{Determination of scanning rate and sample error}

Determination of scanning rate was part of our experimental program aiming at control and extension of a crop microclimate simulation model (Goudriaan \& Waggoner, 1972; Stigter, 1972; Stigter et al., 1973). The experiments were carried out in the summer of 1972 in a 5-ha maize (Zea mays) field situated near Swifterbant in Flevoland, one of the newly reclaimed polder areas of the former Lake Yssel. The maize field was part of a 250 -ha mixed experimental farm in this flat area. Nearest obstructions to wind flow were somewhat less than $1 \mathrm{~km}$ away. The planting pattern was nearly uniform with a row distance of $40 \mathrm{~cm}$ and three plants on $1 \mathrm{~m}$ within the rows.

A Modulog data logging system, with a capacity of 150 measuring points at maximum, was chosen to measure temperature at 100 points in the soil and within and above the canopy and to measure water vapour pressure and omnidirectional wind speed (air movement) at 50 points in total inside and above the crop. Maximum speed of the scanning system was 10 channels per second. At that rate, however, only paper tape could be obtained as output and our printing system could not work. It is generally recommended to avoid this situation because of lack of immediate data checking possibilities (van Bavel, 1967). Therefore we were forced to use 5 channels per second as a maximum scanning rate. If 150 channels are scanned in this way, only once in $30 \mathrm{~s}$ each sensor is recorded. It will depend on the time constant of the sensor, also in the case of being interested in means only, whether this scanning rate is sufficient to obtain a representative value over the period concerned. Moreover, 
turbulence scale and turbulence intensity will play a role. Therefore checks have to be made above the crop as well as at several levels within the canopy.

Preliminary results obtained above grass with our wind and humidity sensors described below revealed that sampling once each half a minute would give indeed differences from what was taken as an accurate estimation of the true mean. These differences were in some cases higher than the limits set, especially for the humidity sensors.

For that reason we modified the scanning system for the simulation model check experiments as follows. The 50 wind and humidity points with a low time-constant sensor were scanned ten times in succession and after the last run the 100 temperature points with a high time-constant sensor were scanned, and so on. Such a set of 600 channels took $120 \mathrm{~s}$. This means that the temperature sensors were now scanned at a rate of once per two minutes and the other sensors at a (mean) rate of once per 12 seconds. We wanted to obtain information on the accuracy of this sample situation that was used throughout our maize crop experiments. We did obtain the preliminary information above grass and the final information above and within the maize crop in the following way.

We estimated or measured time constants $\tau$ of our sensors. As the lowest $\tau$ was $0.5 \mathrm{~s}$, a rule-of-thumb scanning rate of once a second for one channel was adopted for determination of an accurate approximation of the true mean for the low timeconstant sensors, with a supposed standard deviation negligible in comparison to the error limits set. This rule-of-thumb scanning rate was taken once a minute for the high time-constant $(\tau \simeq 30 \mathrm{~s}$ ) thermometers. The latter were however sampled with a much higher speed in our special investigations to give an example that this does not add much information but presumably only reduces noice influences on the sample mean, as is valid for a complete signal sampled at a Shannon $f_{\S}$ (Karbowiak, 1967). This will have no important consequences on the means concerned (Byrne, 1970).

Feeding the computer with the paper tape obtained, we used a Fortran IV program to calculate the means and to perform a simulation of means from measurements at lower scanning rates, all channels being scanned at a rate of once per second. Having made 600 measurements in a 10-minute period, we simulated two runs with 300 measurements once per two seconds by taking even and odd measurements as a run, respectively. The two means obtained in this way differed of course somewhat from the approximation of the true mean. The measurements of the last mentioned two runs were again distributed, each, among two runs of even and odd numbers. This yielded four simulated runs, containing 150 measurements each, of one measurement per each $4 \mathrm{~s}$ within the whole 10-minute run. The computer program went on simulating in this way up to 64 runs (so 64 means) of one measurement each $64 \mathrm{~s}$. The number of measurements left per run now was only 9 or 10 . As we were interested for our fast sensors in the highest deviation (absolute value) from the approximated true mean, among the means determined at each frequency simulated, we determined these worst cases for each 10-minute period. An example is given in Table 1.

To be indeed representative for determination of worst cases, it is necessary that the measurements are done under conditions which contain the highest natural short 
Table 1. Determination of worst cases for different simulated sampling frequencies (one per $4 \mathrm{~s}$ to one per $64 \mathrm{~s}$ inclusive) of air movement for ten 10-minute periods. Results for one measurement per two seconds have been omitted. Measurements were made on two different days, at a height of $2.10 \mathrm{~m}$ in a maize crop $2.40 \mathrm{~m}$ high. Periods 1 to 5 inclusive were obtained with a strong but highly variable wind from the south-west, which only had a short fetch before reaching the measuring place. Mean wind speed over grass at $2 \mathrm{~m}$ height was somewhat more than $5 \mathrm{~m} / \mathrm{s}$, measured air movement by the heated sphere anemometer at the height concerned $1.1 \mathrm{~m} / \mathrm{s}$. Periods 6 to 10 inclusive were obtained with a strong and steady wind from the north-east, which had a fetch long enough even for very reliable wind profile measurements above the maize crop (Bottemanne \& Reitsma, 1973). Mean wind speed over grass at $2 \mathrm{~m}$ height was somewhat less than $5 \mathrm{~m} / \mathrm{s}$, measured air movement by the anemometer $1.6 \mathrm{~m} / \mathrm{s}$.

\begin{tabular}{|c|c|c|c|c|c|c|}
\hline \multirow[t]{2}{*}{ Period (10 min) } & \multirow{2}{*}{$\begin{array}{l}\text { Mean output }(\mu \mathrm{V}) \\
(600 \text { measurements) }\end{array}$} & \multicolumn{5}{|c|}{ Deviation of worst cases (in $10^{-3} \times$ true wind speed) } \\
\hline & & $1 / 4 \mathrm{~s}^{-1}$ & $1 / 8 s^{-1}$ & $1 / 16 s^{-1}$ & $1 / 32 s^{-1}$ & $1 / 64 s^{-1}$ \\
\hline 1 & 281.8 & $<1.0$ & $<4.4$ & $<9.4$ & $<42$ & $<60$ \\
\hline 2 & 283.3 & $<0.4$ & $<1.8$ & $<4.2$ & $<14$ & $<40$ \\
\hline 3 & 278.9 & $<1.6$ & $<2.6$ & $<8.2$ & $<28$ & $<56$ \\
\hline 4 & 293.2 & $<0.8$ & $<4.8$ & $<11.8$ & $<14$ & $<24$ \\
\hline 5 & 293.4 & $<0.6$ & $<3.0$ & $<7.6$ & $<24$ & $<46$ \\
\hline 6 & 261.0 & $<1.6$ & $<4.0$ & $<8.8$ & $<28$ & $<74$ \\
\hline 7 & 270.9 & $<1.4$ & $<3.4$ & $<10.0$ & $<18$ & $<80$ \\
\hline 8 & 264.4 & $<2.0$ & $<3.4$ & $<12.6$ & $<18$ & $<46$ \\
\hline 9 & 271.3 & $<0.4$ & $<1.6$ & $<3.0$ & $<20$ & $<54$ \\
\hline 10 & 268.0 & $<1.4$ & $<1.6$ & $<8.4$ & $<22$ & $<60$ \\
\hline
\end{tabular}

trends of the parameters involved. Normally the sudden changes in incoming radiation when clouds pass along the sun form such conditions for temperature and humidity. Therefore all measurements on these parameters have been done under intermittent sunshine conditions. The time constant of the canopy top is in the order of one minute (Lambert, 1970). Air movement has been measured under two different gustiness conditions (cf. Table 1).

We believe that the results dealt with below provide a good estimation of the maximum possible errors in our cases due to sample frequencies in determinations of 10-minute means. Errors of half-hour means, as needed in our climatic simulation model, will be somewhat smaller and may be derived from means of successive 10-minute errors.

It is once more stated that these considerations and those for the specific sensors below are not dealing with definite aliasing errors. In our final assessment we can not distinguish between errors from changes in standard deviations throughout the change in sample rates, errors from remnants of higher-frequency components, errors from the influence of low-frequency trends and noice errors. Moreover the influence of not taking a correct Shannon frequency as point of departure (approximation of true mean) can not be assessed. We think that in our cases of determining means from the signals of our sensors, the definite assessment will not change much the results, but a proof of this is not given here. The statement is based on our results of meas- 


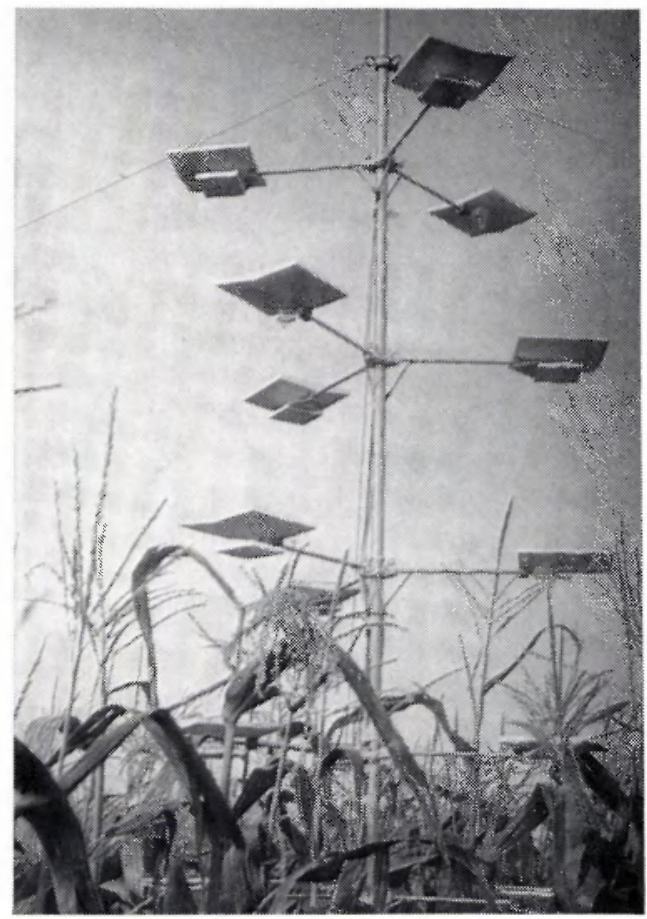

Fig. 1. Measurements of temperature and humidity within and above a matured maize crop. Instruments are visible at heights of $1.80,2.10,2.50,3.00$ and $3.50 \mathrm{~m}$. Temperature sensors are between double radiation protection screens, psychrometers are below a single radiation protection screen. The photograph was made after finishing of a day of measurements, with a low sun (photograph J. van den Brink).

uring temperature, humidity and air movement profiles above and throughout the maize crop (Birnie et al., in prep., Stigter \& Welgraven, 1976; Stigter, 1976).

\section{Temperature}

Our temperature sensors were specially protected all-weather (Comp. Long, 1968) Degussa platina resistance sensors, protected by special screens against radiation influences (Fig. 1). The measured time constant was $35 \mathrm{~s}$ (in a $2 \mathrm{~m} / \mathrm{s}$ turbulent wind speed) and the thermometers were accurately registrated by a special Modulogsystem modification (Birnie et al., in prep.).

As stated above, concerning this sensor we were not interested in determining whether lower sample frequencies than once per minute were of influence on 10minute means. The Shannon rate for a first-order sensor, if it would be applicable, should allow a sample frequency of once per more than one minute $(1 / 2 \tau$; e.g. Tanner, 1963) at $2 \mathrm{~m} / \mathrm{s}$ wind speed for recovering of the complete signal. We therefore took it for granted that using half-hour means determined with a 2-minute sample period would be completely justified (in the range of wind speeds to be expected just above and within the crop).

The results at simulated sample frequencies obtained from the one measurement per second run could however be used to provide a more accurate confirmation of 


\section{WORST CASE ANALYSIS FOR ESTIMATION OF SCANNING RATE}

Table 2. Means of six worst cases of six 10-minute periods per height and 10-minute worst cases in the same hour, as a percentage of the $\mu \mathrm{V}$-signal obtained and in degrees Celsius, for temperature measurements at different heights in a maize canopy. The deviations given concern highest differences observed between a temperature sampled at a rate of one sample per second and one of the 64 approximations of the true mean of one sample per $64 \mathrm{~s}$. Wind situation during these measurements was characterized by an almost constant mean speed of $3.5 \mathrm{~m} / \mathrm{s}$ at $2 \mathrm{~m}$ above grass.

\begin{tabular}{|c|c|c|c|c|}
\hline \multirow[t]{2}{*}{ Height $(\mathrm{cm})$} & \multicolumn{2}{|c|}{$\begin{array}{l}\text { Means of worst cases } \\
\text { ( } 6 \text { periods of } 10 \text { minutes) }\end{array}$} & \multicolumn{2}{|c|}{$\begin{array}{l}\text { Worst case } \\
\text { (one in } 6 \text { periods of } 10 \text { minutes) }\end{array}$} \\
\hline & $\%$ & ${ }^{\circ} \mathrm{C}$ & $\%$ & ${ }^{\circ} \mathrm{C}$ \\
\hline 2 & $<0.9$ & $<0.02$ & $<1.3$ & $<0.03$ \\
\hline 30 & $<0.5$ & $<0.02$ & $<0.6$ & $<0.02$ \\
\hline 120 & $<0.7$ & $<0.04$ & $<0.8$ & $<0.04$ \\
\hline 210 & $<1.4$ & $<0.07$ & $<2.1$ & $<0.10$ \\
\hline 350 & $<1.1$ & $<0.05$ & $<1.4$ & $<0.06$ \\
\hline
\end{tabular}

the example of Suomi (1957), mentioned earlier, with 30-second time-constant sensors. He obtained a mean of 150 samples per hour and observed that even under the most variable conditions means of 60 samples per hour did not differ significantly. We have evaluated this example by the simulation program on the 10 -minute periods as described above. The results are given in Table 2.

From these results one can draw the conclusion that the mean of 600 samples per 10 minutes and the approximated true means of 9 or 10 samples in the same 10 minutes differ in all cases concerned less than the worst case of $0.1{ }^{\circ} \mathrm{C}$. Do we take as an absolute upper limit for a one-hour period the occurring of six successive worst cases for six 10-minute periods, we may state that Suomi's example is extended here. The difference between 3600 samples per hour and 54 to 60 samples in the same hour, measured with a temperature sensor with a time constant in the order of half a minute, is under the highest variable field conditions less than $0.07^{\circ} \mathrm{C}$ (under our wind conditions), and normally appreciably less (Table 2).

The fact that the deviations are highest at the canopy top may stem from the fact that the most actively reacting surface is siuated here (Lambert, 1970). Differences in wind speed and turbulence intensity, so in time constant, play also a role in lower deviations inside the canopy.

\section{Air movement}

Our air movement sensors were thermocouple-type heated sphere anemometers, as designed originally in the Netherlands and improved at our laboratory (Fritschen \& Shaw, 1961; Roer \& Kjolsvik, 1973). An example is shown in Fig. 2. The outer sides of our spheres, made of Woods metal, were coated with a white prime coat and a final layer of 6080 Eastman white reflectance paint (Grum \& Luckey, 1968). Only this reduced the possible error due to performance inside the vegetative cover under conditions of one shaded and one sunlit sphere to a value within the calibration 


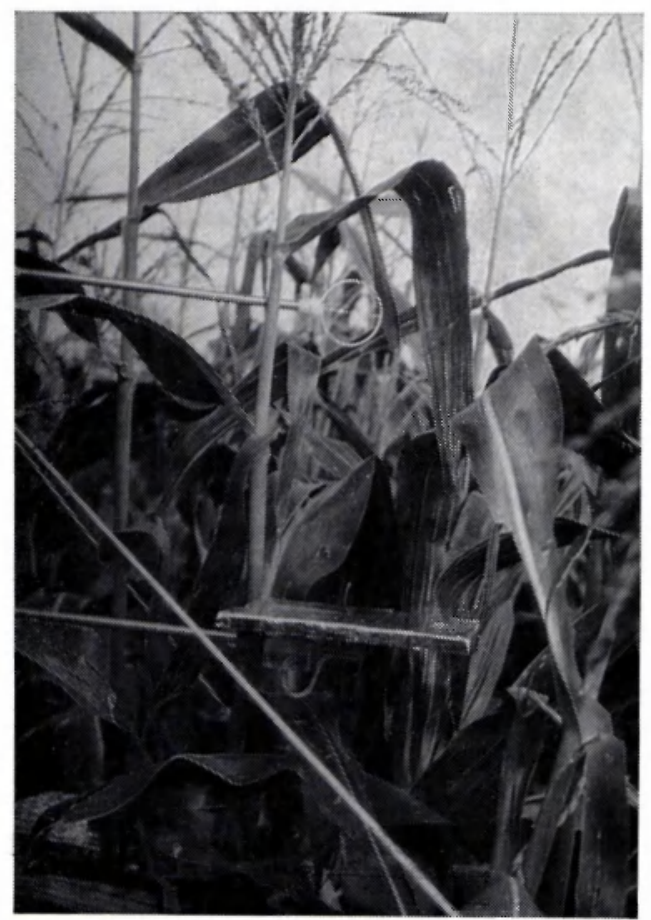

Fig. 2. Measurement of humidity (at 1.80 $\mathrm{m}$, psychrometer under single radiation protection screen) and air movement (at $2.10 \mathrm{~m}$. heated (white) sphere-anemometer) within a matured maize crop (photograph J. van den Brink).

error limits. Due to this coating, wetting of the spheres has to be prevented. After a long time of use the outer layer should be renewed, due to dust deposits.

Time constants could easily be measured by suddenly preventing the heating current to flow through the heated sphere and watching the temperature difference between the junctions going to zero. We found $\tau=17 \mathrm{~s}$ at about $50 \mathrm{~cm} / \mathrm{s}, \tau=11 \mathrm{~s}$ at about $1 \mathrm{~m} / \mathrm{s}$ and $\tau=7 \mathrm{~s}$ at somewhat more than $2 \mathrm{~m} / \mathrm{s}$. The latter value was obtained at $1.50 \mathrm{~m}$ above grass. The first two values were collected at $5 \mathrm{~cm}$ and $120 \mathrm{~cm}$, respectively, in a $2.40 \mathrm{~m}$ maize crop on a day with very high wind speeds. The diminishing $\tau$ of course follows approximatively the square root of wind speed law. Therefore a minimum $\tau$ of between 1 and $2 \mathrm{~s}$ can be expected at a maximum wind speed of $50 \mathrm{~m} / \mathrm{s}$.

At each of the heights shown in Table 3, on two different days, ten 10-minute periods in total were sampled at a rate of one channel per second (see the example in Table 1) and two 10-minute periods in total at a rate of 5 channels per second.

As we were interested in an estimation of the maximum error at the rate of one sample per $12 \mathrm{~s}$, we used an interpolation between the results of one sample per $8 \mathrm{~s}$ and those of one sample per $16 \mathrm{~s}$. It may be appreciated from the figures in Table 1 that a value about halfway the given results is a safe estimation of the 10 -minute worst cases for our scanning speed used in the simulation model field experiments. One can observe from Tables 3 and 4 that the highest worst case occurs at the highest 
Table 3. Worst cases (absolute value of maximum deviation from the approximated true mean) of the means obtained at simultated sample frequencies specified, in ten 10-minute measuring periods, per height, of air movement, at several heights within a maize crop and for one height above short grass. From the percentual errors obtained an estimation is made for the scanning rate $\left(1 / 12 \mathrm{~s}^{-1}\right)$ used in simulation model measurements of air movement profiles within and above the crop.

\begin{tabular}{|c|c|c|c|c|c|c|}
\hline \multirow[t]{2}{*}{ Height $(\mathrm{cm})$} & \multicolumn{2}{|c|}{$\begin{array}{l}\text { Mean wind speed } \\
(\mathrm{cm} / \mathrm{s})\end{array}$} & \multicolumn{2}{|c|}{ Worst case $(\%)$} & \multicolumn{2}{|c|}{ Worst case $\left(1 / 12 s^{-1}\right)$} \\
\hline & $1 / 8 \mathrm{~s}^{-1}$ & $1 / 16 \mathrm{~s}^{-1}$ & $1 / 8 \mathrm{~s}^{-1}$ & $1 / 16 s^{-1}$ & $\%$ & $\begin{array}{l}\text { wind speed } \\
(\mathrm{cm} / \mathrm{s})\end{array}$ \\
\hline 5 & 10 & 10 & $<0.3$ & $<0.9$ & $<0.6$ & $<0.1$ \\
\hline 30 & 13 & 13 & $<0.4$ & $<1.0$ & $<0.7$ & $<0.1$ \\
\hline 120 & 63 & 42 & $<0.6$ & $<1.2$ & $<1.0$ & $<0.7$ \\
\hline 210 & 100 & 170 & $<0.5$ & $<1.3$ & $<1.0$ & $<1.7$ \\
\hline 150 (grass) & 150 & 150 & $<0.5$ & $<1.2$ & $<0.9$ & $<1.4$ \\
\hline
\end{tabular}

level within the canopy. The error is less than $1 \%(\simeq 2 \mathrm{~cm} / \mathrm{s})$. The fact that the percentual error decreases when measurements are made deeper in the canopy may stem from two facts. Firstly, within maize turbulent intensities seem to decrease with depth (Uchijima \& Wright, 1964). Secondly, again the lower wind speeds point into the same direction.

For providing a more absolute limit we analysed, twice for each height, five 2-minute periods, scanned with a speed of 5 channels per second. We now made the assumption that five successive 2-minute worst cases did form such an upper limit. As we analysed the data in the same way as our 10-minute periods the means of the simulated runs of 5 samples per 64 s provided simulation of about one measurement each 12 seconds. Table 4 shows that this appreciably more severe approach only doubled the error values. Therefore from our results one may draw the conclusion that for air movements of about $2 \mathrm{~m} / \mathrm{s}$ or less, and for an instrument with a $\tau$ of $7 \mathrm{~s}$ or higher, under our measuring conditions the maximum percentual error because of a sampling rate of one measurement per $12 \mathrm{~s}$ is expected to be less than $2.0 \%$ for a 10-minute mean. From this value and results not shown here one can estimate

Table 4. Mean worst case (air movement) at a sample speed of $1 / 12 \mathrm{~s}^{-1}$, derived from five successive 2 -minute worst cases with the same sign. The examples given are the worst cases from two 10 -minute periods.

\begin{tabular}{rcrl}
\hline Height $(\mathrm{cm})$ & $\begin{array}{l}\text { Mean wind } \\
\text { speed }(\mathrm{cm} / \mathrm{s})\end{array}$ & \multicolumn{2}{l}{ Mean of worst cases } \\
\cline { 3 - 4 } & & $<$ & wind speed $(\mathrm{cm} / \mathrm{s})$ \\
5 & 9 & $<1.4$ & $<0.2$ \\
30 & 12 & $<1.9$ & $<0.2$ \\
120 & 37 & $<2.0$ & $<0.8$ \\
210 & 150 & $<3.0$ \\
\hline
\end{tabular}


that for a period of half an hour the error will be less than $1.0 \%$ or $2 \mathrm{~cm} / \mathrm{s}$ wind speed at the highest air movement rate considered here.

\section{Water vapour pressure}

Our air humidity sensors were differential thermocouple phychrometers of the type used by Schneider (1969). They were considerably improved in relation to several errors occurring in psychrometry and in relation to their continuous operation for 36 h (Stigter \& Welgraven, 1976; Stigter, 1976). Examples may be seen in Fig. 1 and 2 , protected for direct radiation influence and for the possibility of only one junction being shaded, the other being in a sunlit area.

It is well known that the determination of time constants of ventilated dry and wet bulb hygrometers is complicated by the fact that the bulbs are reacting differently on temperature changes, while the wet bulb is also reacting on humidity changes. As it was preferred not to use artificial ventilation within the vegetation, we must also take into consideration in our case that even for our very small bulb thermocouple psychrometers there is a lower wind speed (air movement) limit below which the psychrometric formula with one psychrometric constant is no longer valid. For our instrument this limit was determined to be $35 \mathrm{~cm} / \mathrm{s}$. The experiments determining this limit were done in an accurate wind tunnel (Stigter \& Welgraven, 1976).

Because of this phenomenon a sudden cease of ventilation over the bulb again introduces a time-constant-like effect. This compoundness of the time constant in relation to natural fluctuations makes it difficult to determine the correct scanning rate. One may state, however, that the most rapid fluctuations of the signal will come from the faster dry bulb reaction on changing ambient temperatures. Its time constant could be calculated to be about $0.5 \mathrm{~s}$. Therefore the rate of one channel per second is in this case also a correct trial for obtaining a good approximation of the true mean. At each of the heights shown in Tables 5 and 6, measurements with a psychro-

Table 5. Worst cases (absolute value of maximum deviation from the approximated true mean) of the means obtained at simulated sample frequencies specified, in ten 10-minute measuring periods, per height, of difference between dry and wet bulb temperature, at several heights within a maize crop and for one height above short grass. From the percentual errors obtained an estimation is made for the scanning rate $\left(1 / 12 \mathrm{~s}^{-1}\right)$ used in simulation model measurements of absolute humidity profiles within and above the crop.

\begin{tabular}{|c|c|c|c|c|c|c|}
\hline \multirow[t]{2}{*}{ Height $(\mathrm{cm})$} & \multicolumn{2}{|c|}{$\begin{array}{l}\text { Dry bulb - wet bulb } \\
\text { temperature difference } \\
\text { in }{ }^{\circ} \mathrm{C}(\text { mean } \Delta T)\end{array}$} & \multicolumn{2}{|c|}{ Worst case $(\%)$} & \multicolumn{2}{|c|}{ Worst case $\left(1 / 12 \mathrm{~s}^{-1}\right)$} \\
\hline & $1 / 8 s^{-1}$ & $1 / 16 s^{-1}$ & $1 / 8 s^{-1}$ & $1 / 16 s^{-1}$ & $\%$ & ${ }^{\circ} \mathrm{C}$ \\
\hline 5 & 2.1 & 2.1 & $<1.4$ & $<1.9$ & $<1.7$ & $<0.04$ \\
\hline 30 & 2.7 & 2.7 & $<1.1$ & $<2.4$ & $<1.8$ & $<0.05$ \\
\hline 120 & 3.9 & 3.8 & $<0.5$ & $<1.2$ & $<1.0$ & $<0.04$ \\
\hline 210 & 5.0 & 5.0 & $<0.6$ & $<1.2$ & $<1.0$ & $<0.05$ \\
\hline 150 (grass) & 9.1 & 9.1 & $<0.2$ & $<0.4$ & $<0.3$ & $<0.03$ \\
\hline
\end{tabular}


Table 6. Mean worst case (dry and wet bulb temperature difference) at a sample speed of $1 / 12 \mathrm{~s}^{-1}$, derived from five successive 2 -minute worst cases with the same sign. The examples given are the worst cases from two 10 -minute periods.

\begin{tabular}{rlll}
\hline Height $(\mathrm{cm})$ & $\begin{array}{l}\text { Mean } \Delta \mathrm{T} \\
\left.\text { ( }{ }^{\circ} \mathrm{C}\right)\end{array}$ & \multicolumn{3}{l}{ Mean of worst cases } \\
\cline { 3 - 4 } & & $\%$ & ${ }^{\circ} \mathrm{C}$ \\
5 & 3.0 & $<3.2$ & $<0.1$ \\
30 & 4.4 & $<1.9$ & $<0.09$ \\
120 & 4.9 & $<1.1$ & $<0.06$ \\
210 & 4.4 & $<1.7$ & $<0.08$ \\
\hline
\end{tabular}

meter were done on two different days during ten 10-minute periods in total at the rate of one channel per second and during two 10-minute periods in total at the rate of five channels per second. Again we are interested in the worst cases at different heights for the sample rate used in our crop experiments, one sample each $12 \mathrm{~s}$. Results are shown in Tables 5 and 6 . They are obtained in the same way as explained for the air movement measurements.

From the 10-minute periods a maximum absolute error of less than $0.05^{\circ} \mathrm{C}$ is derived. The increase in percentual error lower in the canopy, in contrast with the results for air movement, presumably stems from the influence of insufficient ventilation which introduces supplementary fluctuations of the signal. It may be observed from the air movement examples that at 30 and $5 \mathrm{~cm}$ indeed the mean ventilation is normally insufficient at these heights. Measurements clearly showed that also at these heights the air movement fluctuated continuously.

The highest error limit may again be estimated, from the mean of five successive 2-minute worst cases ( 5 measurements in $64 \mathrm{~s}$ ), to be smaller than $0.1^{\circ} \mathrm{C}$ under the conditions given. It can be proved that this implies an error in the water vapour pressure lower than 0.2 mbar for 10 -minute means and lower than about 0.1 mbar for half-hour means.

\section{Discussion of the results}

Whether the accuracies obtained are good enough depends, of course, on the purposes set. For our simulation model the estimated errors because of the sampling rate used are certainly tolerable (Stigter et al., in prep.).

Penman et al. (1967) mention desirable overall accuracies for temperature, humidity and wind speed of $0.1{ }^{\circ} \mathrm{C}, 0.1 \mathrm{mbar}$ and about $1 \mathrm{~cm} / \mathrm{s}$ as ultimate limits for use in profile methods in above crop evapotranspiration calculations. Extending the desirability of these accuracies to profile measurements of humidity and temperature within the crop for calculation of fluxes, providing the profile theory is valid for the site concerned (Byrne \& Rose, 1972), our results would also be usable for that purpose (instrumental errors apart).

Our air movement measurements cannot be used as such because no horizontal components can be derived. They are used as an indication for wet bulb ventilation 
and for calculation of water vapour diffusion and thermal diffusion resistances of the leaf boundary layers (Stigter, 1972).

Further research concerning the influence of scanning rate on approximations of true means needs better information on the characteristics of the signals to be averaged. Trying to use the concept of 'information content of the mean' as a function of the sampling rate, as used in hydrological research (Quimpo \& Yang, 1970; Gupta, 1973), has not yet yielded criteria to be used for micrometeorological signals (Kooijman, 1974). Studying Fourier spectra seems to promise a way to proceed. Also in that case worst case estimations or worst case experiments have to be made regarding the spectra, to include all possible macro- and micrometeorological conditions (Schutten, 1974).

\section{Acknowledgments}

The authors are highly indebted to members of the Department of Physics and Meteorology who cooperated closely in the maize experiments. Concerning discussions on instruments this regards Dr F. A. Bottemanne. Concerning the electronical equipment this regards Ir J. Birnie, Mr P. Jansen and Ing. B. Lammers. Concerning construction of the instruments this regards $\mathrm{Mr} \mathrm{A}$. E. Jansen and his co-operators Messrs W. C. A. M. Hillen, T. Jansen and J. van Zeeland. Concerning assistance in preparing and taking the measurements reported here this regards Messrs A. Verhaaf and A. D. Welgraven. The undergraduate students H. B. M. van der Ham and L. van den Neut carefully assisted in obtainment of the final results by calculations.

Discussions with Ir J. Goudriaan of the Department of Theoretical Production Ecology regarding the applications to the crop climate simulation model, in the early phase of set up of measurements, have been much appreciated. We are grateful to the staff of the Agricultural University Experiment Station at Swifterbant (Flevoland), headed by Dr Ir E. G. Kloosterman, for giving us the possibility to carry out the work reported in a specially prepared maize field.

\section{References}

Anonymous, 1968. Agroclimatological methods. UNESCO Natural Resources Research Series VII, Paris, 392 pp.

Bavel, C. H. M. van, 1967. Use and abuse of information processing by machine. In: E. F. Bradley \& O. T. Denmead (Ed.). The collection and processing of field data, pp. 437-446.

Bottemanne, F. A. \& Tj. Reitsma, 1973. Windprofielmetingen boven grasland; Windprofielmetingen boven mais. Reports 73-1a and 73-1, Laboratory of Physics and Meteorology, Wageningen (Dutch only).

Bradley, E. F. \& O. T. Denmead (Ed.), 1967. The collection and processing of field data. Interscience, New York, $597 \mathrm{pp}$.

Byrne, G. F., 1970. Data logging and scanning rate considerations in micrometeorological experiments. Agric. Met. 7: 415-418.

Byrne, G. F., 1972. Data logging and scanning rate considerations in micrometeorological experiments - a reply. Agric. Met. 9: 287-288.

Byrne, G. F. \& C. W. Rose, 1972. On the determination of vertical fluxes in field crop studies. Agric. Met. 10: 13-17. 


\section{WORST CASE ANALYSIS FOR ESTIMATION OF SCANNING RATE}

Eastin, J. D., F. A. Haskins, C. Y. Sullivan \& C. H. M. van Bavel (Ed.), 1969. Physiological aspects of crop yield. American Society of Agronomists, Madison, $396 \mathrm{pp}$.

Eckardt, F. E. (Ed.), 1968. Functioning of terrestrial eco-systems at the primary production level. UNESCO Natural Resources Research Series V, Paris, 516 pp.

Fritschen, L. J. \& R. H. Shaw, 1961. A thermocouple-type anemometer and its use. Bull. Am. met. Soc. 42: 42-46.

Fuchs, M., 1972. Data logging and scanning rate considerations in micrometeorological experiments - a discussion. Agric. Met. 9: 285-286.

Goudriaan, J. \& P. E. Waggoner, 1972. Simulating both aerial microclimate and soil temperature from observations above the foliar canopy. Neth. J. agric. Sci. 20: 104-124.

Grum, F. \& G. W. Luckey, 1968. Optical sphere paint and a working standard of reflectance. Appl. Optics 7 (11): 2289-2294.

Güpta, V. L., 1973. Information content of time-variant data. Proc. Am. Soc. civ. Engrs (J. hydrol Div.) HY3: 383.

Karbowiak, A. E., 1967. Elements of information theory. In: E. F. Bradley \& O. T. Denmead (Ed.), The collection and processing of field data, pp. 329-372.

Kooijman, J., 1974. Internal report of the Department of Physics \& Meteorology, Agricultural University, Wageningen. (Dutch.)

Kreeb, K., 1974. Ökophysiologie der Pflanzen. G. Fisher Verlag, Stuttgart, 211 pp.

Lambert, John L., 1970. Thermal response of a plant canopy to drifting cloud shadows. Ecology 51: 143-149.

Lemon, E., D. W. Stewart \& R. W. Shawcroft, 1971. The sun's work in a cornfield. Science 174: 371-378.

Long, I. F., 1968. Instruments and techniques for measuring the microclimate of crops. In: R. M. Wadsworth (Ed.), The measurement of environmental factors in terrestrial ecology. Blackwell, Oxford, pp. 1-32.

Luxton, R. E., A. J. Dyer \& L. G. Kemeny, 1967. In a discussion after the section on micrometeorology. In: E. F. Bradley \& O. T. Denmead (Ed.), The collection and processing of field data, pp. 70-71.

Monteith, J. L., 1973. Principles of environmental physics. Edward Arnold, London, 241 pp.

Paltridge, G. W., A. C. Dilley, J. R. Garratt, G. I. Pearman, W. Shepherd \& D. J. Connor, 1972. The Rutherglen experiment on sherpa wheat: environmental and biological data. Tech. Pap. CSIRO, Div. atmosph. Physics 22. CSIRO, Melbourne, $41 \mathrm{pp} .+$ data file.

Penman, H. L., D. E. Angus \& C. H. M. van Bavel, 1967. Microclimatic factors affecting evaporation and transpiration. In: R. M. Hagan et al. (Ed.), Irrigation of agricultural lands, Ch. 26. American Society of Agronomists, Madison, $1180 \mathrm{pp}$.

Quimpo, R. G. \& J. Yang, 1970. Sampling considerations in stream discharge and temperature measurements. Water Resour. Res. 6: 1771-1774.

Roer, P. \& M. Kjölsvik, 1973. Equipment for measuring low air velocity. Agric. Met. 12: 281-296.

Rosenberg, N. J., 1974. Microclimate: the biological environment. John Wiley, New York, 315 pp.

San Pietro, A., F. A. Greer \& T. J. Army (Ed.), 1967. Harvesting the sun. Academic Press, New York, $342 \mathrm{pp}$.

Schneider, T., 1969. A thermocouple psychrometer and its use for the measurement of water vapour pressure near the earth's surface. Arch. Met. Geophys. Biokl. Ser. B 17: 391-402.

Schutten, R., 1974. Het verwerken van meteorologische waarnemingen. Rapport baccalaureaatsopdracht, Afd. Meettechniek, T.H. Twente. (Dutch.)

Sesták, Z., J. Catský \& P. G. Jarvis (Ed.), 1971. Plant photosynthetic production; manual of methods. Junk, The Hague, 818 pp.

Sétlik, I. (Ed.), 1970. Prediction and measurement of photosynthetic productivity. Proceedings of the IBP/PP technical meeting (Trebon). PUDOC, Wageningen, $632 \mathrm{pp}$.

Slatyer, R. O. (Ed.), 1973. Plant response to climatic factors. UNESCO Ecology and Conservation Series V, Paris, 504 pp.

Smith, L. P. (Ed.), 1975a. Progress in plant biometeorology, the effect of weather and climate 
on plants, Vol. 1: Period 1963-1974. Division C in Progress in Biometeorology Series. Swets \& Zeitlinger, Amsterdam, 474 pp.

Smith, L. P., 1975b. Methods in agricultural meteorology. Elsevier, Amsterdam, $240 \mathrm{pp}$.

Stigter, C. J., 1972. Leaf diffusion resistance to water vapour and its direct measurement. I. Introduction and review concerning relevant factors and methods. Meded. LandbHogesch. Wageningen 72-3: 1-47.

Stigter, C. J., 1976. Water vapour pressure within a maize crop. Arch. Met. Geophys. Biokl. Ser. $\mathrm{B} 24$, in press.

Stigter, C. J., J. Birnie \& B. Lammers, 1973. Leaf diffusion resistance to water vapour and its direct measurement. II. Design, calibration and pertinent theory of an improved leaf diffusion resistance meter. Meded. LandbHogesch. Wageningen 73-15: 1-55.

Stigter, C. J. \& A. D. Welgraven, 1976. An improved radiation protected differential thermocouple psychrometer for crop environment. Arch. Met. Geophys. Biokl. Ser. B 24, in press.

Suomi, V. E., 1957. Double-psychrometer lift apparatus - University of Wisconsin. In: H. H. Lettau \& B. Davidson (Ed.), Exploring the atmosphere's first mile, Vol. I: 183-187.

Tanner, C. B., 1963. Basic instrumentation and measurements for plant environment and micrometeorology. Soils Bull. No 6, Dep. Soil Sci., Univ. Wisc., Madison. No consecutive pagination.

Uchijima, Z. \& J. L. Wright, 1964. An experimental study of air flow in a corn plant air layer. Bull. Natn. Inst. agric. Sci. (Japan) A 11: 19-65.

Vries, D. A. de \& N. H. Afgan (Ed.), 1975. Heat and mass transfer in the biosphere, Part I: Transfer processes in the plant environment. Scripta Book Company, Washington, 594 pp.

Wareing, P. F. \& J. P. Cooper, 1971. Potential crop production, a case study. Heinemann, London, $387 \mathrm{pp}$. 